\title{
Google searches for bruxism, teeth grinding, and teeth clenching during the COVID-19 pandemic
}

\author{
Elif Kardeş ${ }^{1} \mathbb{D} \cdot$ Sinan Kardeş² \\ Received: 20 November 2020 / Accepted: 1 May 2021 / Published online: 29 June 2021 \\ (c) Springer Medizin Verlag GmbH, ein Teil von Springer Nature 2021
}

\begin{abstract}
Purpose Whether coronavirus disease 2019 (COVID-19) pandemic has an impact on bruxism represents an important gap of knowledge. This study evaluated the trends in Google searches, as an indication of public interest and demand, for bruxism and its symptoms during the COVID-19 pandemic.

Methods Google Trends was queried for bruxism, teeth grinding, and teeth clenching both worldwide and in the United States. Two periods in 2020 (March 15-May 9 and May 10-October 17) were compared to similar periods of 2016-2019 to investigate both initial and short-term interest.

Results The relative search volume of bruxism, teeth grinding, and teeth clenching was not significantly different between 2020 and 2016-2019 worldwide or in the United States in the March 15-May 9 period. Only the search for teeth grinding showed an increase worldwide. In the May 10-October 17 period, the relative search volume of bruxism, teeth grinding, and teeth clenching all was significantly higher in 2020 compared to 2016-2019 both worldwide and in the United States. Conclusion The study showed that the relative search volume for bruxism, teeth grinding, and teeth clenching, as an indication of public interest and demand, was increased both worldwide and in the United States during the May-October 2020 period compared to similar periods of the previous 4 years. Dentists should address this increased public interest and demand for information seeking for bruxism. Follow-up studies monitoring long-term interest as a real-time surveillance and evaluating whether increased internet searches are linked to an actual increase or worsening of bruxism and its symptoms in the clinic are required.
\end{abstract}

Keywords Google Trends · Internet search engines $\cdot$ Psychological distress $\cdot$ Dentistry $\cdot$ Dentists

\section{Google-Suchanfragen zu Bruxismus, Zähneknirschen und Zähnepressen während der COVID-19-Pandemie}

\section{Zusammenfassung}

Ziel Ob die COVID(,,coronavirus disease 2019“)-Pandemie einen Einfluss auf Bruxismus hat, stellt eine wesentliche Forschungslücke dar. In dieser Studie wurden die Trends in den Google-Suchanfragen, als Anhaltspunkt für öffentliches Interesse und die entsprechende Nachfrage, für Bruxismus und seine Symptome während der COVID-19-Pandemie ausgewertet.

Methoden Google Trends wurde für Bruxismus, Zähneknirschen und Zähnepressen sowohl weltweit als auch in den USA abgefragt. Zwei Zeiträume im Jahr 2020 (15.03.-09.05. und 10.05.-17.10.) wurden mit ähnlichen Zeiträumen der Jahre 2016-2019 verglichen, um sowohl das initiale als auch das kurzfristige Interesse zu untersuchen.

Elif Kardes

elifkardes@gmail.com

Sinan Kardeş

sinan.kardes@istanbul.edu.tr
Istanbul, Turkey

2 Department of Medical Ecology and Hydroclimatology, Istanbul Faculty of Medicine, Istanbul University, Istanbul, Turkey 
Ergebnisse Das relative Aufkommen der Suchanfragen zu Bruxismus, Zähneknirschen und Zähnepressen unterschied sich im Zeitraum vom 15.03.-09.05. weder weltweit noch in den USA statistisch signifikant zwischen 2020 und 2016-2019. Nur die Suche nach Zähneknirschen zeigte weltweit einen Anstieg. Im Untersuchungszeitraum 10.05.-17.10. war das relative Suchvolumen bezüglich Bruxismus, Zähneknirschen und Zähnepressen im Jahr 2020 im Vergleich zu 2016-2019 sowohl weltweit als auch in den USA signifikant höher.

Schlussfolgerung Die Studie zeigte, dass das relative Suchvolumen für Bruxismus, Zähneknirschen und Zähnepressen als Hinweis auf öffentliches Interesse und Nachfrage sowohl weltweit als auch in den Vereinigten Staaten während des Zeitraums von Mai bis Oktober 2020 im Vergleich zu ähnlichen Zeiträumen der vorangegangenen 4 Jahre erhöht war. Zahnärzte sollten dieses erhöhte öffentliche Interesse und die Nachfrage nach Informationen über Bruxismus ansprechen. Folgestudien, die das langfristige Interesse im Sinne einer Echtzeitüberwachung beobachten und auswerten, ob die erhöhte Internetsuche mit einer tatsächlichen Zunahme oder einer Verstärkung von Bruxismus und seinen Symptomen in der Klinik verbunden ist, sind erforderlich.

Schlüsselwörter Google Trends · Internetsuchmaschinen · Psychische Belastungen · Zahnmedizin · Zahnärzte

\section{Introduction}

The rapid spread of the coronavirus disease 2019 (COVID19) pandemic resulted in $38,202,956$ confirmed cases and $1,087,069$ deaths worldwide, as of October 15, 2020 [1]. To control its widespread transmission, containment measures were implemented including strict quarantine and lockdown. These measures triggered an economic recession and financial crisis with an unprecedented rise in unemployment $[2,3]$. The health crisis coupled with its negative social and economic consequences have led to a considerable increase in levels of psychological distress and sleep disorders as well as in alcohol consumption among the general population [4-8].

Google (Google LLC, Mountain View, CA, USA) searches data have been used to track public interest in a broad range of dental topics such as dental carries, molar incisor hypomineralization, and amber necklace [9-11]. Furthermore, in a recent infodemiological study the seasonality of Google searches of bruxism and its symptoms was evaluated [12]. In the context of the COVID-19 pandemic, Google searches data have been leveraged to evaluate public interest in COVID-19 terms [13, 14], mental health issues $[15,16]$, and insomnia [17]. All these studies demonstrate Google searches as being a powerful tool in monitoring public interest.

Although psychological distress, sleep disorders as well as high alcohol consumption are well-documented risk factors for bruxism [18-22], whether COVID-19 pandemic has an impact on bruxism represents an important gap of knowledge. To address this major gap, the present study evaluated the trends in Google searches, as an indication of public interest and demand, for bruxism and its symptoms during the COVID-19 pandemic.

\section{Materials and methods}

The present study followed the recommendations of the recent article by Mavragani et al. addressing the methodological framework in using Google Trends in health research [23]. The Google Trends tool and data are explained in detail elsewhere [24, 25]. In brief, Google Trends, a freely accessible tool, provides information on trends of keywords that people search for on Google. It allows exploring variations both in individual countries and worldwide. Google Trends normalizes search data to the time period and region selected, and then transforms it to a $0-100$ scale for making comparisons easier. Greater values indicate greater relative search volume (RSV).

The Google Trends was queried for the three keywords: (1) bruxism, (2) teeth grinding, and (3) teeth clenching. Time period of search was set to January 01,2016 , to October 20,2020, with a selection of all categories. This search strategy was performed worldwide and in the United States, the most affected country in terms of COVID-19 cases and deaths. All RSV data were downloaded for exploring the trends.

Two periods in 2020 (March 15-May 9 and May 10-October 17) were compared to similar periods of the previous 4 years (2016-2019) to investigate both initial and short-term interest. In addition, a time series chart was generated to visualize the trends for bruxism, teeth grinding, and teeth clenching in 2016-2019 and 2020. Weekly data were transformed to monthly data for the time series chart. The World Health Organization (WHO) declared a pandemic just before mid-March; therefore, dates after March 15, 2020 were chosen in comparisons. The first period (March 15-May 9) coincides with implemented quarantine measures just after the WHO declaration of a pandemic; therefore, it provides the interest during the initial phase of the pandemic. The second period provides the interest during the pandemic period, which coincides with 
lightening/lifting the imposed quarantine measures. A generalized estimating equation with a gamma distribution was utilized in the comparisons. Statistical analysis was performed in SPSS ${ }^{\circledR}$ v. 21.0 (IBM, Armonk, NY, USA) and the time series chart was generated on Excel v. 14.3.7 (Microsoft, Redmond, WA, USA) and data were presented as per standard recommendations [26].

\section{Results}

In the initial period, March 15-May 9, the relative search volume of bruxism and teeth clenching was not significantly different between 2020 and 2016-2019 worldwide or in the United States. In this period, the worldwide relative search volume of teeth grinding (change: $11.5 \%, p=0.017$ ) was significantly higher in 2020 than in 2016-2019; however, it was not significantly different in the United States (change: $5.2 \%, p=0.304$ ) (Table 1).

In the May 10-October 17 period, the relative search volume of bruxism (worldwide, change: $23.6 \%, p<0.001$; United States, change: $9.8 \%, p=0.005)$, teeth grinding (worldwide, change: $24.9 \%, p<0.001$; United States, change: $17.2 \%, p<0.001$ ), and teeth clenching (worldwide, change: $22.5 \%, p<0.001$; United States, change: $13.6 \%, p=0.002$ ) was significantly higher in 2020 than in 2016-2019 (Table 1).

Fig. 1 shows that the relative search volume of bruxism, teeth grinding, and teeth clenching was numerically similar in 2020 and in 2016-2019 in March; then it was numerically higher in all the other months (April through October) in 2020 compared to the mean of 2016-2019 both worldwide and in the United States.

\section{Discussion}

The study found that the relative search volume of bruxism, teeth grinding, and teeth clenching was not significantly different between 2020 and 2016-2019 worldwide or in the United States in the initial period, March 15-May 9. Only the search for teeth grinding showed an increase worldwide. However, after the initial period, the relative search volume of bruxism, teeth grinding, and teeth clenching increased and was significantly higher in 2020 compared to 2016-2019 both worldwide and in the United States.

In the initial period, relative search volume of bruxism and teeth clenching was not different between 2020 and 2016-2019 worldwide. In addition, the relative search volume of bruxism, teeth grinding and teeth clenching was not different between 2020 and 2016-2019 in the United States. Previous studies using Google Trends showed that in this initial period the relative search volume of COVID19 terms (e.g., coronavirus), COVID-19 symptoms (e.g., cough, diarrhea, and loss of smell) and some mental health issues (e.g., anxiety) increased but the relative search volume of general health issues (e.g., dermatologic conditions and rheumatic diseases) decreased [13-16, 27-34]. We believe that our finding (no difference) in the initial period is important considering the previous studies' results that showed a significant decrease in general health issues reflecting a shift of public interest from general health issues to COVID-19 [32-34]. Therefore, our finding indicates that the public remarkably searched for bruxism and its symptoms in the initial pandemic period. After the initial period, relative search volume of bruxism, teeth grinding and teeth clenching all were significantly increased compared to similar periods of the previous 4 years. This finding may

Table 1 Relative search volume of bruxism, teeth grinding, and teeth clenching worldwide and in the United States

Tab. 1 Relatives Aufkommen von Anfragen zu Bruxismus, Zähneknirschen und Zähnepressen weltweit und in den USA

\begin{tabular}{|c|c|c|c|c|c|c|c|c|}
\hline & \multicolumn{4}{|c|}{ March 15-May 9} & \multicolumn{4}{|c|}{ May $10-$ October 17} \\
\hline & 2020 & 2016-2019 & $\%$ Change & $P$ value & 2020 & 2016-2019 & $\%$ Change & $P$ value \\
\hline \multicolumn{9}{|l|}{ Bruxism } \\
\hline Worldwide & $\begin{array}{l}47.6 \\
(44.4-51.1)\end{array}$ & $\begin{array}{l}45.0 \\
(42.3-47.1)\end{array}$ & $\begin{array}{l}6.8 \\
(-2.7-16.3)\end{array}$ & 0.152 & $\begin{array}{l}52.2 \\
(50.6-53.8)\end{array}$ & $\begin{array}{l}42.2 \\
(40.9-43.6)\end{array}$ & $\begin{array}{l}23.6 \\
(18.2-29.0)\end{array}$ & $<0.001$ \\
\hline $\begin{array}{l}\text { United } \\
\text { States }\end{array}$ & $\begin{array}{l}61.3 \\
(57.1-65.8)\end{array}$ & $\begin{array}{l}63.2 \\
(58.2-68.6)\end{array}$ & $\begin{array}{l}-3.0 \\
(-13.5-7.5)\end{array}$ & 0.581 & $\begin{array}{l}67.7 \\
(64.5-71.0)\end{array}$ & $\begin{array}{l}61.6 \\
(59.0-64.4)\end{array}$ & $9.8(2.7-17.0)$ & 0.005 \\
\hline \multicolumn{9}{|c|}{ Teeth grinding } \\
\hline Worldwide & $\begin{array}{l}83.0 \\
(76.7-89.8)\end{array}$ & $\begin{array}{l}74.4 \\
(71.7-77.2)\end{array}$ & $\begin{array}{l}11.5 \\
(1.9-21.2)\end{array}$ & 0.017 & $\begin{array}{l}89.5 \\
(86.9-92.2)\end{array}$ & $\begin{array}{l}71.7 \\
(70.1-73.4)\end{array}$ & $\begin{array}{l}24.9 \\
(20.2-29.5)\end{array}$ & $<0.001$ \\
\hline $\begin{array}{l}\text { United } \\
\text { States }\end{array}$ & $\begin{array}{l}68.9 \\
(63.3-75.0)\end{array}$ & $\begin{array}{l}65.5 \\
(62.7-68.3)\end{array}$ & $\begin{array}{l}5.2 \\
(-4.8-15.2)\end{array}$ & 0.304 & $\begin{array}{l}73.7 \\
(71.4-76.1)\end{array}$ & $\begin{array}{l}63.0 \\
(61.4-64.5)\end{array}$ & $\begin{array}{l}17.2 \\
(12.4-21.9)\end{array}$ & $<0.001$ \\
\hline \multicolumn{9}{|c|}{ Teeth clenching } \\
\hline Worldwide & $\begin{array}{l}64.6 \\
(58.3-71.7)\end{array}$ & $\begin{array}{l}61.0 \\
(56.6-65.7)\end{array}$ & $\begin{array}{l}6.0 \\
(-7.5-19.5)\end{array}$ & 0.376 & $\begin{array}{l}71.2 \\
(65.5-77.4)\end{array}$ & $\begin{array}{l}58.1 \\
(55.3-61.1)\end{array}$ & $\begin{array}{l}22.5 \\
(10.7-34.4)\end{array}$ & $<0.001$ \\
\hline $\begin{array}{l}\text { United } \\
\text { States }\end{array}$ & $\begin{array}{l}62.9 \\
(58.6-67.5) \\
\end{array}$ & $\begin{array}{l}61.9 \\
(57.9-66.2) \\
\end{array}$ & $\begin{array}{l}1.6 \\
(-8.3-11.5) \\
\end{array}$ & 0.748 & $\begin{array}{l}70.7 \\
(66.0-75.6) \\
\end{array}$ & $\begin{array}{l}62.2 \\
(59.9-64.5) \\
\end{array}$ & $\begin{array}{l}13.6 \\
(4.9-22.4) \\
\end{array}$ & 0.002 \\
\hline
\end{tabular}

Relative search volume values are presented as a mean ( $95 \%$ confidence interval) (generalized estimating equations) 

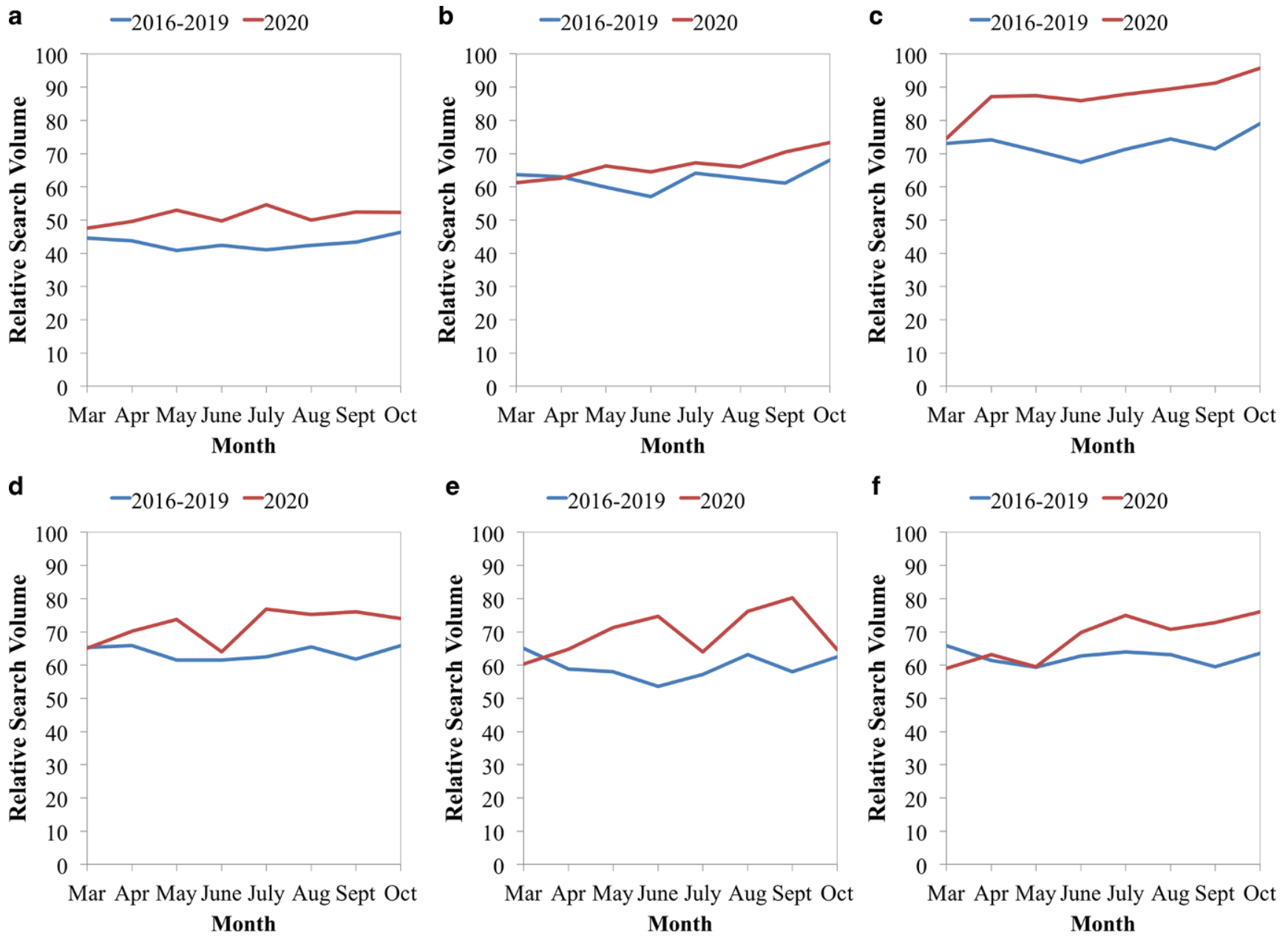

Fig. 1 Relative search volume of (a) bruxism worldwide, (b) bruxism in the United States, (c) teeth grinding worldwide, (d) teeth grinding in the United States, (e) teeth clenching worldwide, (f) teeth clenching in the United States. The data of October was based on partial data of October Abb. 1 Relatives Volumen von Suchanfragen für (a) Bruxismus weltweit, (b) Bruxismus in den USA, (c) Zähneknirschen weltweit, (d) Zähneknirschen in den USA, (e) Zähneknirschen weltweit, (f) Zähneknirschen in den USA. Die Daten vom Oktober basierten auf Teildaten vom Oktober

indicate that the COVID-19 pandemic had a negative impact on bruxism and its symptoms. Several factors might have contributed to this observed increase. COVID-19-related deaths, strict quarantine/lockdown measures, and economic recession/financial crisis/rise in unemployment have led to considerable increases in the levels of psychological distress in the general public $[4,6]$. Furthermore, alcohol consumption has increased during the pandemic [8]. Since psychological distress as well as high alcohol consumption are well-documented risk factors for bruxism [18-22], the increase in intensity of these risk factors might have led to or worsen existing bruxism. Although the present findings require verification with clinical studies, healthcare providers should address the increased public interest and demand for information regarding bruxism.

Previous studies evaluated the trends in Google searches for mental health issues and insomnia [15-17]. Hoerger et al. compared mental health-related Google searches in the United States during the initial pandemic period (first 40 days following March 11, 2020) with the prepandemic period [15]. They found significant increases in searches related to worry, panic, and anxiety; however, no significant changes were detected in searches related to depression, loneliness, or suicide in the initial pandemic period compared with the prepandemic period [15]. They suggested continued surveillance of Google searches for these terms because changes in these terms may occur later [15]. Ayers et al. evaluated the search terms for anxiety or panic in combination with attack in the United States. They found that acute anxiety searches were higher than expected for the initial pandemic period (first 58 days following March 13, 2020) [16]. In a study examining Google searches for insomnia worldwide and in the United States, Zitting et al. showed a decrease in searches for insomnia in March and then a large increase in April and May 2020 [17]. The 
present study provides insights into the potential impact of the COVID-19 pandemic on bruxism and its symptoms.

Two previous cross-sectional studies using online surveys to investigate the population's self-reported bruxism symptoms and their worsening during the COVID-19 pandemic are available in the literature [35, 36]. In the study by Emodi-Perlman et al., a total of 700 participants from Israel and 1092 participants from Poland fully completed the survey [35]. They found that 40 and $32 \%$ of Israeli and 68 and $50 \%$ of Polish participants reported possible/ probable awake bruxism and possible/probable sleep bruxism, respectively [35]. They also showed that 16 and $13 \%$ of Israeli and 34 and $28 \%$ of Polish participants reported awake bruxism aggravation and sleep bruxism aggravation, respectively [35]. In the other cross-sectional study by Javaid et al., 1021 participants from around the world completed the survey [36]. They found that $13 \%$ of participants reported bruxism symptoms during the pandemic [36]. Furthermore, in an overview article, Hassan and Khier hypothesized that awake bruxism might be triggered/worsened during the pandemic due to increased/accumulated stress [37]. The design of the present study differs from the previously published two survey studies and our results indicate increased internet searches for bruxism and its symptoms during the pandemic.

\section{Limitations}

There were limitations with the present study. First, we only analyzed Google engine searches. However, since approximately $90 \%$ of all internet searches conducted on it [38], Google searches may be representative for all internet searches. Second, Google Trends does not allow analyzing in various subpopulations (e.g., male/female). Therefore, the results are only applicable for whole population. Third, internet use may be lower in some subpopulations (e.g., illiterate, older adults); hence, these subpopulations might be excluded or underrepresented. Fourth, our search strategy was by no means exhaustive-rather, focused only on internet searches for bruxism and its symptoms (i.e., teeth grinding and teeth clenching). Adding some other keywords such as headache, toothache, neck pain, and jaw pain into our search strategy would have managed to allow a better interpretation of the study results. Fifth, we have no information on the motivation or intention of internet searches for bruxism, teeth grinding and teeth clenching. It is possible that an increased number of popular scientific healthrelated publications on bruxism may lead to a rise in its internet searches or increased interest in seeking head and neck pain-related information might contribute to searches for bruxism. Considering these possible factors/reasons behind the observed increase in internet searches, it is not possible to attribute all the changes only to the pandemic.
Furthermore, the study provided no evidence of whether the COVID-19 pandemic has caused an increasing demand for dental treatment. Sixth, the global results of the study should be interpreted with caution and by bearing in mind the facts that the seasons are reversed between northern and southern hemispheres and previous studies showed seasonality in internet searches of several health topics including bruxism [12]. Seventh, we were able to investigate only initial and short-term interest. A follow-up study is needed to monitor long-term interest as a real-time surveillance. Lastly, whether the present findings are associated with actual increase or worsening in bruxism and its symptoms deserves future evaluation.

\section{Conclusion}

The present study showed that the relative search volume for bruxism, teeth grinding, and teeth clenching, as an indication of public interest and demand, was increased both worldwide and in the United States during the May-October 2020 period compared to similar periods of the previous 4 years. Dentists should address this increased public interest and demand for information seeking for bruxism. Follow-up studies monitoring long-term interest as a real-time surveillance and evaluating whether increased internet searches are linked to an actual increase or worsening of bruxism and its symptoms in the clinic are required.

Conflict of interest E. Kardeş and S. Kardeş declare that they have no competing interests.

\section{References}

1. World Health Organization https://covid19.who.int/. Accessed 15 Oct 2020

2. OECD (2020) News release: G20 GDP growth quarterly national accounts. Paris. https://www.oecd.org/sdd/na/g20-gdp-growth-Q22020.pdf/ (Created 14 Sept 2020). Accessed 15 Oct 2020

3. OECD (2020) OECD unemployment rates news. Paris. https:// www.oecd.org/sdd/labour-stats/unemployment-rates-oecd-09-2020. pdf/ (Created 9 Sept 2020). Accessed 15 Oct 2020

4. Xiong J, Lipsitz O, Nasri F, Lui LMW, Gill H, Phan L, ChenLi D, Iacobucci M, Ho R, Majeed A, McIntyre RS (2020) Impact of COVID-19 pandemic on mental health in the general population: a systematic review. J Affect Disord. https://doi.org/10.1016/j.jad. 2020.08.001

5. Marroquín B, Vine V, Morgan R (2020) Mental health during the COVID-19 pandemic: effects of stay-at-home policies, social distancing behavior, and social resources. Psychiatry Res 293:113419. https://doi.org/10.1016/j.psychres.2020.113419

6. Singh S, Roy D, Sinha K, Parveen S, Sharma G, Joshi G (2020) Impact of COVID-19 and lockdown on mental health of children and adolescents: a narrative review with recommendations. Psychiatry Res 293:113429. https://doi.org/10.1016/j.psychres.2020.113429 
7. Holman EA, Thompson RR, Garfin DR, Silver RC (2020) The unfolding COVID-19 pandemic: a probability-based, nationally representative study of mental health in the United States. Sci Adv 6:eabd5390. https://doi.org/10.1126/sciadv.abd5390

8. Pollard MS, Tucker JS, Green HD Jr (2020) Changes in adult alcohol use and consequences during the COVID-19 pandemic in the US. JAMA Netw Open 3:e2022942. https://doi.org/10.1001/ jamanetworkopen.2020.22942

9. Aguirre PE, Coelho M, Oliveira T, Rios D, Cruvinel AF, Cruvinel T (2018) What can Google inform us about people's interests regarding dental caries in different populations? Caries Res 52:177-188. https://doi.org/10.1159/000485107

10. Aguirre PEA, Strieder AP, Lotto M, Oliveira TM, Rios D, Cruvinel AFP, Cruvinel T (2020) Are the Internet users concerned about molar incisor hypomineralization? An infoveillance study. Int J Paediatr Dent 30:27-34. https://doi.org/10.1111/ipd.12579

11. Strieder AP, Aguirre PEA, Lotto M, Cruvinel AFP, Cruvinel T (2019) Digital behavior surveillance for monitoring the interests of Google users in amber necklace in different countries. Int J Paediatr Dent 29:603-614. https://doi.org/10.1111/ipd.12500

12. Kardeş S, Kardeş E (2019) Seasonality of bruxism: evidence from Google trends. Sleep Breath 23:695-701. https://doi.org/10.1007/ s11325-019-01787-6

13. Husain I, Briggs B, Lefebvre C, Cline DM, Stopyra JP, O'Brien MC, Vaithi R, Gilmore S, Countryman C (2020) Fluctuation of public interest in COVID-19 in the United States: retrospective analysis of Google trends search data. JMIR Public Health Surveill 6:e19969. https://doi.org/10.2196/19969

14. Effenberger M, Kronbichler A, Shin JI, Mayer G, Tilg H, Perco P (2020) Association of the COVID-19 pandemic with Internet search volumes: a Google trendsTM analysis. Int J Infect Dis 95:192-197. https://doi.org/10.1016/j.ijid.2020.04.033

15. Hoerger M, Alonzi S, Perry LM, Voss HM, Easwar S, Gerhart JI (2020) Impact of the COVID-19 pandemic on mental health: real-time surveillance using Google trends. Psychol Trauma 12:567-568. https://doi.org/10.1037/tra0000872

16. Ayers JW, Leas EC, Johnson DC, Poliak A, Althouse BM, Dredze M, Nobles AL (2020) Internet searches for acute anxiety during the early stages of the COVID-19 pandemic. JAMA Intern Med. https:// doi.org/10.1001/jamainternmed.2020.3305

17. Zitting KM, Lammers-van der Holst HM, Yuan RK, Wang W, Quan SF, Duffy JF (2020) Google trends reveal increases in internet searches for insomnia during the COVID-19 global pandemic. J Clin Sleep Med. https://doi.org/10.5664/jcsm.8810

18. Kuhn M, Türp JC (2018) Risk factors for bruxism. Swiss Dent J 128:118-124

19. Guo H, Wang T, Niu X, Wang H, Yang W, Qiu J, Yang L (2018) The risk factors related to bruxism in children: a systematic review and meta-analysis. Arch Oral Biol 86:18-34. https://doi.org/10.1016/j. archoralbio.2017.11.004

20. Castroflorio T, Bargellini A, Rossini G, Cugliari G, Deregibus A (2017) Sleep bruxism and related risk factors in adults: a systematic literature review. Arch Oral Biol 83:25-32. https://doi.org/10.1016/ j.archoralbio.2017.07.002

21. Castroflorio T, Bargellini A, Rossini G, Cugliari G, Deregibus A (2017) Sleep bruxism in adolescents: a systematic literature review of related risk factors. Eur J Orthod 39:61-68. https://doi.org/10. 1093/ejo/cjw012

22. Melo G, Duarte J, Pauletto P, Porporatti AL, Stuginski-Barbosa J, Winocur E, Flores-Mir C, De Luca Canto G (2019) Bruxism: an umbrella review of systematic reviews. J Oral Rehabil 46:666-690. https://doi.org/10.1111/joor.12801

23. Mavragani A, Ochoa G (2019) Google trends in infodemiology and infoveillance: methodology framework. JMIR Public Health Surveill 5:e13439. https://doi.org/10.2196/13439
24. Kardeş S (2019) Seasonal variation in the internet searches for gout: an ecological study. Clin Rheumatol 38:769-775. https://doi.org/ 10.1007/s10067-018-4345-2

25. Kardeş S (2019) Seasonal variation in the internet searches for psoriasis. Arch Dermatol Res 311:461-467. https://doi.org/10.1007/ s00403-019-01921-0

26. Misra DP, Zimba O, Gasparyan AY (2021) Statistical data presentation: a primer for rheumatology researchers. Rheumatol Int 41:43-55. https://doi.org/10.1007/s00296-020-04740-z

27. Rajan A, Sharaf R, Brown RS, Sharaiha RZ, Lebwohl B, Mahadev S (2020) Association of search query interest in gastrointestinal symptoms with COVID-19 diagnosis in the United States: infodemiology study. JMIR Public Health Surveill 6:e19354. https:// doi.org/10.2196/19354

28. Senecal C, Gulati R, Lerman A (2020) Google trends insights into reduced acute coronary syndrome admissions during the COVID19 pandemic: infodemiology study. JMIR Cardio 4:e20426. https:// doi.org/10.2196/20426

29. Walker A, Hopkins C, Surda P (2020) Use of Google trends to investigate loss-of-smell-related searches during the COVID-19 outbreak. Int Forum Allergy Rhinol 10:839-847. https://doi.org/10. 1002/alr.22580

30. Kardeş S (2021) Public interest in spa therapy during the COVID19 pandemic: analysis of Google trends data among Turkey. Int J Biometeorol. https://doi.org/10.1007/s00484-021-02077-1

31. Kardeş S, Kuzu AS, Pakhchanian H, Raiker R, Karagülle M (2020) Population-level interest in anti-rheumatic drugs in the COVID-19 era: insights from Google trends. Clin Rheumatol. https://doi.org/ 10.1007/s10067-020-05490-w

32. Esen-Salman K, Akın-Çakıcı Ö, Kardeş S, Salman A (2021) Public interest in dermatologic symptoms, conditions, treatments, and procedures during the COVID-19 pandemic: insights from Google trends. Dermatol Ther 34:e14895. https://doi.org/10.1111/ dth. 14895

33. Kardeş S, Kuzu AS, Raiker R, Pakhchanian H, Karagülle M (2021) Public interest in rheumatic diseases and rheumatologist in the United States during the COVID-19 pandemic: evidence from Google trends. Rheumatol Int 41:329-334. https://doi.org/10.1007/ s00296-020-04728-9

34. Kardeş S, Erdem A, Gürdal H (2021) Public interest in musculoskeletal symptoms and disorders during the COVID-19 pandemic: infodemiology study. Z Rheumatol. https://doi.org/10.1007/ s00393-021-00989-2

35. Emodi-Perlman A, Eli I, Smardz J, Uziel N, Wieckiewicz G, Gilon E, Grychowska N, Wieckiewicz M (2020) Temporomandibular disorders and Bruxism outbreak as a possible factor of orofacial pain worsening during the COVID-19 pandemic-concomitant research in two countries. J Clin Med 9:3250. https://doi.org/10.3390/ jcm9103250

36. Javaid A, Yousufi S, Riaz Z, Yasir Y, Tajik I, Ahmad N (2021) A global perspective in self-reported brushing, bruxism and tmd symptoms during COVID-19 lockdown. STETHO 2:1-9. https:// doi.org/10.5281/zenodo.4543641

37. Hassan KA, Khier SE (2020) Awake bruxism intensified during COVID-19 pandemic by cumulative stress-An overview. J Clin Res Dent 3:1-3

38. Statcounter https://gs.statcounter.com/search-engine-market-share/. Accessed 15 Oct 2020

Publisher's Note Springer Nature remains neutral with regard to jurisdictional claims in published maps and institutional affiliations. 